\title{
Blood vitamin status in chronic alcoholics after a single dose of polyvitamin. A preliminary report
}

\author{
Sisir K. MaJumdar \\ B.Sc., M.B. B.S. \\ G. K. ShaW \\ F.R.C.Psych., D.P.M.

\begin{abstract}
Allan D. Thomson
B.Sc., M.B., Ch.B., M.R.C.P., Ph.D.

Elmdene Alcoholic Treatment Unit, Bexley Hospital, Kent, and Gastroenterology \& Liver Unit, Greenwich District Hospital, London
\end{abstract}

\begin{abstract}
Summary
Blood vitamin status $\left(B_{1}, B_{2}\right.$ and $\left.B_{6}\right)$ was assessed by erythrocytic enzyme activation tests in 7 male and 1 female chronic alcoholics (mean age ( \pm s.d.), $43 \cdot 12$ (13.7) years; range, 25-64 years) on admission and $6 \mathrm{hr}$ later on the same day after oral administration of a single dose of polyvitamin. Seven out of 8 patients were found to be deficient in vitamin $B_{1}, 5$ in $B_{6}$ and none in $B_{2}$. But after single-dose oral therapy, tendency to improvement of blood vitamin status was clearly evident in all patients. It is therefore suggested that a subgroup of chronic alcoholics may benefit from oral supplementation of vitamins. Clinical implications of vitamin deficiency in chronic alcoholics are briefly discussed.
\end{abstract}

\section{Introduction}

Multiple vitamin deficiency due to poor dietary intake, impaired absorption, inability metabolically to transform the inactive vitamin (in diet or drugs) to its biologically active metabolite as a result of hepatic hypo-function or impaired tissue storage in chronic alcoholics is well documented (Thomson, 1978; Thomson, Rae and Majumdar, 1980b). Vitamin deficiency may limit repair of ethanol-induced physical damage. It is, therefore, important to ensure that current therapeutic measures effectively replete the deficiencies. Deficiencies are normalized quite well after i.v. polyvitamin therapy (Majumdar, Shaw and Thomson, 1981). The blood vitamin status $\left(B_{1}\right.$, $B_{2}, B_{6}$ ) was tested in randomly selected chronic alcoholics both before and after a single oral dose of one tablet of polyvitamin in order to make a preliminary assessment of their utilizing capacity of the administered vitamins.

\section{Patients}

Eight patients ( 7 male, 1 female; mean age ( \pm s.d.),
$43 \cdot 12(13 \cdot 7)$ years; range $25-64$ years) were randomly $\vec{\oplus}$ selected on admission for the study. Their con-음 sumption of ethanol was equivalent to more than $80 \mathrm{~g} /$ day of absolute ethanol for more than 5 years. 3 They had a few stigmata of hepatic damage (i.e. $\stackrel{\infty}{\circ}$ liver palm, spider naevi, clubbing and hepatomegaly $\mathcal{S}$ in some patients). There were no clinical featurgs $\overrightarrow{0}$ suggesting intestinal malabsorption, diarrhoea (9r) vomiting.

\section{Treatment}

All patients were given one tablet of Orovite (Bencard) which contains $50 \mathrm{mg}$ thiamine hydro- $\frac{\circ}{\varnothing}$ chloride, $5 \mathrm{mg}$ riboflavin, $5 \mathrm{mg}$ pyridoxine hydrochloride, $200 \mathrm{mg}$ nicotinamide and $100 \mathrm{mg}$ ascorbic $\overrightarrow{\vec{B}}$ acid.

\section{Methods}

Samples of blood were of $4 \mathrm{ml}$ in special vials $\frac{\bar{\partial}}{7}$ (containing acid citrate and dextrose as preservative to prevent haemolysis) from each patient on admis- 3 sion before starting treatment and also $6 \mathrm{hr}$ later on the same day. The following erythrocyte enzyme activation tests were used according to methods of Heller, Salkeld and Korner (1974a, b). Erythrocyte $\frac{}{5}$ transketolase (ETK) for vitamin $B_{1}$; glutathione? reductase (EGR) for $B_{2}$. Pyridoxal-5-phosphate (PALP) for vitamin $B_{6}$ was directly estimated in red $N$ blood cells by methods of Lumeng and $\mathrm{Li}$ (1974).

The activation co-efficient is represented by $\alpha . \alpha$ ETK is a measure of vitamin $B_{1}$ status and is the ratio $\omega$ of increased erythrocyte transketolase activity (with thiamine pyrophosphate (TPP)) to the originale activity (without TPP). ETK $_{0}$ represents the amount ${ }_{\mathscr{Q}}$ of the apoenzyme fraction of the enzyme trans-? ketolase without the addition of TPP (normal, $\frac{0}{\circ}$ $>70 \mu \mathrm{mol} / \mathrm{l})$. Similarly, $\alpha \mathrm{EGR}$ is a parameter for $\stackrel{\mathrm{D}}{\mathrm{D}}$ riboflavin status and is the ratio of increased $\frac{\rho}{\odot}$ 
TABLE 1. Vitamin utilization status in chronic alcoholics after a single oral dose of Ovorite (one tablet) - $6 \mathrm{hr}$ later

\begin{tabular}{|c|c|c|c|c|c|c|c|c|c|c|}
\hline \multirow{3}{*}{$\begin{array}{c}\text { Patient } \\
\text { no. }\end{array}$} & \multirow[b]{3}{*}{ Age } & \multirow[b]{3}{*}{ Sex } & \multicolumn{4}{|c|}{ Vitamin $\mathbf{B}_{\mathbf{1}}$} & \multirow{2}{*}{\multicolumn{2}{|c|}{$\frac{\text { Vitamin } B_{2}}{\alpha \mathrm{EAR}}$}} & \multirow{2}{*}{\multicolumn{2}{|c|}{$\frac{\text { Vitamin } \mathbf{B}_{\mathbf{6}}}{\text { PALP }}$}} \\
\hline & & & \multicolumn{2}{|c|}{ ETK $_{0}$} & \multicolumn{2}{|c|}{$\alpha$ ETK } & & & & \\
\hline & & & Before & After & Before & After & Before & After & Before & After \\
\hline 1 & 53 & $\mathbf{M}$ & $78 \cdot 6$ & $79 \cdot 5$ & 1.02 & 1.01 & 0.97 & 0.88 & $7 \cdot 3$ & $9 \cdot 2$ \\
\hline 2 & 25 & M & $66 \cdot 5$ & $67 \cdot 9$ & 1.05 & 1.08 & 0.95 & 0.93 & $10 \cdot 7$ & $15 \cdot 7$ \\
\hline 3 & 34 & $\mathbf{F}$ & $63 \cdot 4$ & $86 \cdot 3$ & $1 \cdot 12$ & 1.06 & $1 \cdot 19$ & 1.07 & $4 \cdot 4$ & 6.6 \\
\hline 4 & 43 & $\mathbf{M}$ & $47 \cdot 3$ & 53.6 & $1 \cdot 21$ & 1.02 & 1.02 & 0.96 & $4 \cdot 5$ & $8 \cdot 6$ \\
\hline 5 & 55 & $\mathbf{M}$ & $62 \cdot 4$ & $62 \cdot 7$ & 1.06 & 1.04 & $1 \cdot 14$ & 1.07 & $3 \cdot 7$ & $5 \cdot 7$ \\
\hline 6 & 64 & $\mathbf{M}$ & $42 \cdot 8$ & 50.4 & $1 \cdot 16$ & 1.09 & 0.98 & $1 \cdot 01$ & 4.9 & $9 \cdot 2$ \\
\hline 7 & 28 & $\mathbf{M}$ & 55.5 & $63 \cdot 0$ & $1 \cdot 16$ & 1.09 & 0.99 & 0.98 & $3 \cdot 1$ & $5 \cdot 1$ \\
\hline 8 & 43 & $\mathbf{M}$ & $34 \cdot 2$ & 40.6 & $1 \cdot 34$ & $1 \cdot 17$ & 1.05 & 1.03 & 5.9 & 9.9 \\
\hline Mean & $43 \cdot 12$ & $M=7$ & $56 \cdot 33$ & 63.0 & $1 \cdot 14$ & 1.07 & 1.03 & 0.99 & $5 \cdot 56$ & $8 \cdot 75$ \\
\hline \pm s.d. & $13 \cdot 70$ & $F=1$ & $14 \cdot 34$ & 15.06 & $0 \cdot 10$ & 0.05 & 0.08 & 0.06 & $2 \cdot 44$ & $3 \cdot 32$ \\
\hline \multicolumn{3}{|c|}{ Normal values } & \multicolumn{2}{|c|}{$>70 \mu \mathrm{mol} / 1$} & \multicolumn{2}{|c|}{$\leqslant 1 \cdot 15$} & \multicolumn{2}{|c|}{$\leqslant 1 \cdot 19$} & \multicolumn{2}{|c|}{$>5(\mathrm{ng} / \mathrm{ml})$} \\
\hline
\end{tabular}

ETK $_{0}$, erythrocyte transketolase; EGR, glutathione reductase; PALP, pyridoxal-5-phosphate.

erythrocyte glutathione reductase activity (with flavin adenine dinucleotide (FAD) to the basal activity (without FAD). Pyridoxine is inactive as such and is converted in the body to its biologically active metabolite-pyridoxal-5-phosphate (PALP) with the help of adenosine triphosphate (ATP) and PALP is measured directly in the erythrocytes.

\section{Results}

Results ( \pm s.d.) are given in Table 1).

\section{Vitamin $B_{1}$}

Seven out of 8 were found to be deficient in $\mathrm{ETK}_{0}$ (mean ( \pm s.d.), 56.33 (14.34)), it improved in all patients but normalized only in one and the mean still remained below normal (mean ( \pm s.d.), 63.0 $(15 \cdot 06)) . \alpha E T K$ was lower than normal in 4 out of 8 but returned to normal in all cases except one (patient no. 8).

\section{Vitamin $B_{2}$}

$\alpha E G R$ was within normal limits on admission and it improved after therapy.

\section{Vitamin $B_{6}$}

PALP was lower than normal in 5 out of 8 patients and it was considerably improved after treatment.

\section{Discussion}

Post-treatment blood vitamin status improved in all patients and a tendency to further improvement on continued oral treatment was clearly evident in all of them.

Vitamin deficiency $\left(B_{1}, B_{2}\right.$ and $\left.B_{6}\right)$ in chronic alcoholics may be partially attributed to low dietary $\mathrm{i}_{\text {ntake, impaired absorption, deficient metabolic }}$ transformation to their active metabolites due to hepatic hypofunction and impaired tissue storage (Thomson, 1978; Thomson et al., 1980b). All these vitamins are converted in the body, especially in the liver, and erythrocytes are converted to their biologically active metabolites with the help of ATP which then act as essential co-enzymes in vital functions, i.e. thiamine to TPP, pyridoxine to PALP, and FAD, which is the main co-enzyme form of riboflavin.

The biologically active co-enzyme form of vitamin $B_{6}$ (PALP) in erythrocytes and plasma has been shown to reflect the nutritional status (Rossouw et al., 1977). $\alpha \mathrm{ETK}$ and $\alpha \mathrm{EGR}$ also reflect the vitamin status for thiamine and riboflavin respectively (Heller et al., 1974a, b) and hence the nutritional state as well. The present observations indicate the need for relevant vitamin supplementation in chronic alcoholics and also supports the inclusion of vitamins in a conventional detoxification regime for chronic alcoholics.

Vitamin deficiency frequently accompanies alcoholism in the U.K. (Thomson, 1978; Thomson et al., 1980b) and also in the U.S.A. (Leevy and Baker, 1970; Leevy, Thomson and Baker, 1970) and may limit repair of physical damage induced by chronic ethanol ingestion.

The provision of nutrients which can be utilized at the subcellular level may therefore limit the degree of permanent brain damage and enhance tissue repair (Thomson et al., 1980a). The findings reported in this paper suggest that polyvitamin therapy may be of value but the response to sustained- as opposed to single-dose administration has yet to be evaluated. 


\section{Acknowledgment}

We thank the Department of Vitamin and Nutrition Research, F. Hoffman-La Roche \& Co., Ltd, Basle, Switzerland, for arranging the estimations of blood vitamins in our patients.

\section{References}

Heller, S., Salkeld, R.M. \& Korner, W.F. (1974a) Vitamin $B_{1}$ status in pregnancy. American Journal of Clinical Nutrition, 27, 1221

Heller, S., Salkeld, R.M. \& Korner, W.F. (1974b) Riboflavin status in pregnancy. American Journal of Clinical Nutrition, 27, 1225.

Leevy, C.M. \& BAKer, H. (1970) Nutritional deficiencies in liver disease. Medical Clinics of North America, 54, 467.

LeEvy, C.M., Thomson, A.D. \& BAKeR, H. (1970) Vitamins and liver injury. American Journal of Clinical Nutrition, 23, 493.

LUMENG, L. \& LI, T.K. (1974) Vitamin $B_{6}$ metabolism in chronic alcohol abuse. Pyridoxal phosphate levels in plasma and the effects of acetaldehyde on pyridoxal phosphate synthesis and degradation in human erythrocytes. Journal of Clinical Investigation, 53, 693.

Majumdar, S.K., Shaw, G.K. \& Thomson, A.D. (1981) Vitamin utilization status in chronic alcoholics. Inter- 0 national Journal of Vitamin and Nutrition Research (Switzerland), (in press).

Rossouw, J.E., Labadarios, D., McConnell, J.B., Davis, M. \& Williams, R. (1977) Plasma pyridoxal phosphate levels in fulminant hepatic failure and the effects of $\mathbb{D}$ parenteral supplementation. Scandinavian Journal of
Gastroenterology, 12, 123. Gastroenterology, 12, 123 .
homson, A.D. (1978) Alcohol and nutrition. Clinics in $\vec{\circ}$ Endocrinology and Metabolism, 7, 405.

Thomson, A.D., Majumdar, S.K., Shaw, G.K., Lishman, W.A., RON, M. \& ACKER, W. (1980a) Mechanisms of brain damage in alcoholic liver disease. Gut, 21, A.447.

Thomson, A.D., RAE, S.A. \& Majumdar, S.K. (1980b) Malnutrition in the alcoholic. In: Medical Consequences of 3 Alcohol Abuse, Ch. 6, pp. 103-155 (Ed by Clarke, P.M.S. \& o Kricka, L.J.). Ellis Horwood, Chichester (U.K.) (in press). 